\title{
CHEMOSPHERE
}

\section{Henry's law constant, octanol-air partition coefficient and supercooled liquid vapor pressure of carbazole as a function of temperature: Application to gas/particle partitioning in the atmosphere}

\author{
Mustafa Odabasi ${ }^{\text {a,* }}$, Banu Cetin ${ }^{\text {a }}$, Aysun Sofuoglu ${ }^{b}$ \\ ${ }^{a}$ Faculty of Engineering, Department of Environmental Engineering, Dokuz Eylul University, Kaynaklar Campus, \\ 35160 Buca, Izmir, Turkey \\ ${ }^{\mathrm{b}}$ Izmir Institute of Technology, Faculty of Engineering, Department of Chemical Engineering, \\ 35460 Gulbahce-Urla, Izmir, Turkey
}

Received 1 December 2004; received in revised form 11 May 2005; accepted 17 May 2005

Available online 12 July 2005

\begin{abstract}
The Henry's law constant for carbazole was experimentally determined between 5 and $35^{\circ} \mathrm{C}$ using a gas-stripping technique. The following equation was obtained for dimensionless Henry's law constant $\left(H^{\prime}\right)$ versus temperature $(T, K)$ :

$$
\ln H^{\prime}=-3982(T, K)^{-1}+1.01
$$

Temperature-dependent octanol-air partition coefficients $\left(K_{\mathrm{OA}}\right)$ and supercooled liquid vapor pressures $\left(P_{\mathrm{L}}, \mathrm{Pa}\right)$ of carbazole were also determined using the GC retention time method. The temperature dependence of $K_{\mathrm{OA}}$ and $P_{\mathrm{L}}$ were explained by the following:

$$
\begin{aligned}
& \log K_{\mathrm{OA}}=4076 /(T, K)-5.65 \\
& \log P_{\mathrm{L}}(\mathrm{Pa})=-3948(T, K)^{-1}+11.84
\end{aligned}
$$

The gas and particle-phase carbazole concentrations measured previously in Chicago, IL in 1995 was used for gas/ particle partitioning modeling. Octanol based absorptive partitioning model consistently underpredicted the gas/particle partition coefficients $\left(K_{\mathrm{p}}\right)$ for all sampling periods. However, overall there was a good agreement between the measured $K_{\mathrm{p}}$ and soot-based model predictions.
\end{abstract}

(C) 2005 Elsevier Ltd. All rights reserved.

Keywords: Carbazole; Henry's law constant; Vapor pressure; Octanol-air partition coefficient; Gas/particle partitioning

\footnotetext{
* Corresponding author. Tel.: +90 232453 1008; fax: +90 232 4530922.

E-mail address: mustafa.odabasi@deu.edu.tr (M. Odabasi).
}

\section{Introduction}

Carbazole is one of the major nitrogen containing polycyclic aromatic hydrocarbons in fossil fuels (i.e., 
coal, crude oil, oils derived from the pyrolysis of oil shales) (Benedik et al., 1998; Williams and Nazzal, 1998). Carbazole is emitted from coal and wood combustion and it is also found in cigarette smoke (Liang and Pankow, 1996; Smith and Hansch, 2000; Ross et al., 2002). Although carbazole is useful as an industrial raw material for dyes, medicines, insecticides and plastics, it is also known to be an environmental pollutant. USA imported more than $4 \times 10^{6} \mathrm{~kg}$ of carbazole in 1997 (Benedik et al., 1998). It is widely used and emitted into the environment but little is known about the environmental fate of carbazole. Carbazole has been detected in the atmosphere, river sediments and groundwater as well as at contaminated sites (Grosser et al., 1995; Johansen et al., 1997; Benedik et al., 1998; Odabasi et al., 1999). Environmental occurrence of carbazole causes concern because it is known to be mutagenic and toxic and classified as a "benign tumorigen" (Smith and Hansch, 2000). Carbazole also readily undergoes radical chemistry to generate the genotoxic hydroxynitrocarbazoles (Benedik et al., 1998).

Like other semivolatile organic compounds (SOCs) carbazole is found in the ambient air in gas phase and as sorbed to aerosols (Odabasi et al., 1999). The fate, transport and removal of SOCs from the atmosphere by dry and wet deposition processes are strongly influenced by their gas-particle partitioning (Bidleman, 1988). Considerable research has been conducted over the past decades on gas-particle partitioning of SOCs. Adsorption onto particle surface and absorption into aerosol organic matter are the two proposed mechanisms describing this process. For many years, the partitioning has been described with an empirical relationship based on the supercooled liquid vapor pressure $\left(P_{\mathrm{L}}\right)$ (Pankow, 1987). Absorptive partitioning of SOCs into the organic material phase of atmospheric aerosols based on the octanol-air partititon coefficient $\left(K_{\mathrm{OA}}\right)$ has also received attention (Finizio et al., 1997; Harner and Bidleman, 1998a). Recently, a soot-carbon partition model has also been used to describe the gas-particle distribution of polycyclic aromatic hydrocarbons (PAHs) (Dasch and Eisenreich, 2000). Dasch and Eisenreich (2000) concluded that the adsorption onto aerosol soot carbon dominates partitioning of PAHs between the gas and particle phases.

The octanol-air partition coefficient is also a key descriptor of chemical partitioning between the atmosphere and other environmental organic phases such as soil and vegetation (Harner et al., 2000; Shoeib and Harner, 2002). The Henry's law constant $(H)$ is another important parameter that plays a fundamental role in predicting the transport, behavior and fate of SOCs in the environment and it is required to model the chemical transfer between air and water. The objective of this study was to determine the Henry's law constant, octanol-air partition coefficient and supercooled liquid vapor pressure of carbazole as a function of temperature. Henry's law constant was measured at four different environmental temperatures by a commonly used gas-stripping technique. Temperature-dependent $K_{\mathrm{OA}}$ values and supercooled liquid vapor pressures for carbazole PAHs were determined using the GC retention time method.

\section{Experimental}

\subsection{Henry's law constant}

The gas-stripping apparatus consisted of a $75 \mathrm{~cm}$ by $5 \mathrm{~cm}$ diameter water-jacketed glass reactor filled with 11 deionized water at a depth of $50 \mathrm{~cm}$. In order to check the consistency of the results, phenanthrene was also added into the reactor with carbazole as a reference compound having previously measured Henry's law constants. The carbazole and phenathrene were prepared in $1 \mathrm{ml}$ methanol and spiked into the water in the reactor to obtain concentrations of less than $2 \%$ of their solubility (40 and $10 \mu \mathrm{g}^{-1}$ for carbazole and phenanthrene,

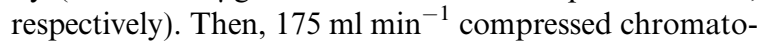
graphic grade $\mathrm{N}_{2}$ was passed through a $40-\mu \mathrm{m}$ fritted glass diffuser from the bottom of the reactor. Prior to the reactor, the $\mathrm{N}_{2}$ purge gas was saturated with water vapor using a gas washing bottle filled with deionized water. Flow rates of $\mathrm{N}_{2}$ were measured using a flow meter and the temperature was controlled by a constant-temperature circulated water bath.

Vapor phase carbazole and phenanthrene were captured by an XAD2 resin filled glass column. Water samples $(5 \mathrm{ml})$ were drawn through a valve located at the base of the reactor at the start and end of each experimental period $(\sim 24 \mathrm{~h})$.

Gas-phase samples were extracted into dichloromethane (DCM) in an ultrasonic bath for $20 \mathrm{~min}$. The extract was concentrated and solvent exchanged into hexane using a rotary evaporator. Water samples were liquidliquid extracted three times with $5 \mathrm{ml}$ DCM using a separatory funnel. Finally, both air and water samples were reduced to their final volumes of $1 \mathrm{ml}$ under a gentle stream of pure nitrogen.

The samples were analyzed with a gas chromatograph (GC) (Agilent 6890N) equipped with a mass selective detector (Agilent 5973 inert MSD). A capillary column (HP5-ms, $30 \mathrm{~m}, 0.25 \mathrm{~mm}, 0.25 \mu \mathrm{m}$ ) was used. The initial oven temperature was held at $50^{\circ} \mathrm{C}$ for 1 min and raised to $100^{\circ} \mathrm{C}$ at $25^{\circ} \mathrm{C} \mathrm{min}^{-1}, 100-250{ }^{\circ} \mathrm{C}$ at $5^{\circ} \mathrm{C} \mathrm{min}^{-1}$. The injector and ion source temperatures were 250 and $230^{\circ} \mathrm{C}$, respectively. High purity helium was used as the carrier gas at constant flow mode with a linear velocity of $35 \mathrm{~cm} \mathrm{~s}^{-1}$. The MSD was run in selected ion-monitoring mode. Compounds were identified based on their retention times, target and qualifier ions. 


\subsection{Octanol-air partition coefficients and supercooled liquid vapor pressure}

The classical method for determining $K_{\mathrm{OA}}$ values for SOCs is the generator column method that has been extensively used to measure the $K_{\mathrm{OA}}$ of various SOCs (Harner and Mackay, 1995; Harner and Bidleman, 1996; Harner and Bidleman, 1998b; Harner et al., 2000; Harner and Shoheib, 2002; Shoeib and Harner, 2002). However, this method requires long experimental periods, especially at low temperatures and for compounds with low volatility, and requires several analytical steps having the potential to introduce error to the measured $K_{\mathrm{OA}}$ value (Wania et al., 2002). Recent studies have indicated that relative gas chromatographic retention times on a non-polar stationary phase can be used to determine the $K_{\mathrm{OA}}$ and the energy of phase transfer between octanol and gas phase $\left(\Delta U_{\mathrm{OA}}\right)$ for nonpolar SOCs (Su et al., 2002; Wania et al., 2002). The only requirements for this method are knowledge of the temperature-dependent $K_{\mathrm{OA}}$ of a standard reference compound and directly measured $K_{\mathrm{OA}}$ values for a sufficient number of calibration compounds (Wania et al., 2002).

The gas chromatographic (GC) retention time method for the determination of supercooled liquid vapor pressure of SOCs has also been commonly used (Lei et al., 1999; Wong et al., 2001; Lei et al., 2002). Most conventional methods used for vapor pressure measurement (i.e. gas saturation and effusion) yield the vapor pressure of the solid substance, whereas the GC retention time method directly gives the vapor pressure of supercooled liquid. The GC retention time method is recommended as one of the most suitable methods for the determination of the vapor pressure of low volatility compounds because it allows the relatively rapid determination of temperature dependent vapor pressures of many compounds (Lei et al., 2002). However, the method's success depends on the availability of reliable vapor pressure data for similar compounds to serve as standard reference and calibration compounds.

A gas chromatograph (GC) (Agilent 6890N) equipped with a mass selective detector (Agilent 5973N MSD) and a capillary column with a non-polar stationary phase (HP5-ms, $30 \mathrm{~m}, 0.25 \mathrm{~mm}, 0.25 \mu \mathrm{m}$ ) was used to determine isothermal retention times of PAHs. The injector and ion source temperatures were 250 and $230{ }^{\circ} \mathrm{C}$, respectively. High purity helium was used as the carrier gas at constant flow mode with a linear velocity of $35 \mathrm{~cm} \mathrm{~s}^{-1}$. The PAH solution contained phenanthrene, carbazole, and pyrene with concentrations of $4 \mu \mathrm{g} \mathrm{ml}^{-1}$. The isothermal retention times of these compounds were determined at nine different temperatures $\left(150-210{ }^{\circ} \mathrm{C}\right)$ in triplicate. The MSD was run in full scan mode and PAHs were identified using spectral library search.

\subsection{Quality control}

Blank XAD2 resin and water samples $(n=3)$ were prepared to determine if there was any contamination during sample handling and preparation for analysis. The carbazole amounts found in blanks were $2.4 \pm 0.5$ and $1.1 \pm 0.1 \mathrm{ng}$ (average $\pm \mathrm{SD}$ ) for air and water samples, respectively. Blank amounts were significantly lower than the sample amounts (22 $\pm 9 \mathrm{ng}$ for air samples, $137 \pm 21 \mathrm{ng}$ for water samples).

A backup column was also placed in series with first glass column in order to determine possible breakthrough of chemicals. The average amount found on this backup column was about 3.0 and $96 \mathrm{ng}$ for carbazole and phenanthrene, respectively that was very close to blank values of 2.4 and $95 \mathrm{ng}$. This result clearly indicated that there was not any breakthrough of chemicals.

The MSD was tuned daily. If any difference more than $10 \%$ absolute abundance was observed from that observed during the previous daily tuning, the instrument was retuned. A calibration standard was checked for every 12-h period to confirm GC/MS performance. Five point calibration curves were used to calibrate the analytical system. In all cases the $r^{2}$ was $>0.999$.

Procedural recoveries of phenanthrene and carbazole were determined externally and they were $>90 \%$. Since the recoveries were high, sample amounts were not corrected for procedural recoveries.

\section{Data analysis}

\subsection{Henry's law constant}

The Henry's Law constant is often expressed as (Bamford et al., 1999):

$H=P_{\mathrm{g}} / C_{w}$

where $P_{\mathrm{g}}$ is the gas-phase partial pressure (atm) and $C_{w}$ is the dissolved concentration $\left(\mathrm{mol} \mathrm{l}^{-1}\right)$.

Using the ideal gas law $[p=(n R T) / V]$ to convert partial pressure to moles per liter $\left(\mathrm{mol} \mathrm{l}^{-1}\right)$ of air, dimensionless Henry's law constant $\left(H^{\prime}\right)$ can be obtained as

$H^{\prime}=H / R T$

where $R$ is the ideal gas constant $(0.082051$ atm $\mathrm{mol}^{-1} \mathrm{~K}^{-1}$ ) and $T$ is the absolute temperature $(\mathrm{K})$.

The temperature dependence of $H^{\prime}$ can be depicted as (Bamford et al., 1999):

$\ln H^{\prime}=-\Delta H_{\mathrm{H}} / R T+\Delta S_{\mathrm{H}} / R$

where $\Delta H_{\mathrm{H}}\left(\mathrm{kJ} \mathrm{mol}^{-1}\right)$ and $\Delta S_{\mathrm{H}}\left(\mathrm{kJ} \mathrm{mol}^{-1} \mathrm{~K}^{-1}\right)$ are the enthalpy and entropy of the phase change from the dissolved phase to the gas phase, respectively. After directly measuring $H^{\prime}$ at different temperatures, $\ln H^{\prime}$ versus $1 / T$ 
can be plotted and $\Delta H_{\mathrm{H}}$ and $\Delta S_{\mathrm{H}}$ can be obtained from the slope and the intercept, respectively.

The experimental procedure was applied at four different temperatures including $35,25,15$ and $5{ }^{\circ} \mathrm{C}$ and replicated three times for each temperature. $H^{\prime}$ was calculated as follows:

$H^{\prime}=C_{\mathrm{g}} /\left[\left(C_{w(n)}+C_{w(n+1)}\right) / 2\right]$

where $C_{\mathrm{g}}\left(\mathrm{ng}^{-1}\right)$ is the time-integrated gas-phase carbazole concentration and $C_{w(n)}$ and $C_{w(n+1)}$ are the dissolved carbazole concentrations $\left(\mathrm{ng}^{-1}\right)$ measured at the beginning and end of air sampling period, respectively.

\subsection{Octanol-air partition coefficient}

The retention time of a substance on a gas chromatographic column $\left(t_{\mathrm{R}}\right)$ is proportional to partition coefficient between stationary phase and gas phase $\left(K_{\mathrm{SA}}\right)$ (Wania et al., 2002). For an appropriate stationary phase, the partitioning equilibrium between stationary phase and gas phase may be similar to the partitioning equilibrium between octanol and air. This assumes that the ratio of the activity coefficients of compound $i$ and of the reference compound in octanol $\left(\gamma_{\mathrm{Oi}} / \gamma_{\mathrm{Oref}}\right)$ is equal to the ratio of activity coefficients of these two compounds in the stationary phase $\left(\gamma_{\mathrm{Si}} / \gamma_{\mathrm{Sref}}\right)$. Using these assumptions and the van't Hoff equation that expresses the temperature dependence of $K_{\mathrm{OA}}$, octanol-air partition coefficient $\left(K_{\mathrm{OA}}\right)$ of a compound $i$ and of a reference compound can be related to their retention times $\left(t_{\mathrm{Ri}}\right.$ and $t_{\text {Rref }}$ ) on the same GC column as (Wania et al., 2002):

$$
\begin{aligned}
& \ln K_{\mathrm{OAi}}=\left(\Delta U_{\mathrm{OAi}} / \Delta U_{\mathrm{OAref}}\right) \ln K_{\mathrm{OAref}}+C \\
& \begin{aligned}
\ln \left(t_{\mathrm{Ri}} / t_{\mathrm{Rref}}\right) & =\left[\left(\Delta U_{\mathrm{OAi}} / \Delta U_{\mathrm{OAref}}\right)-1\right] \ln K_{\mathrm{OAref}}+C \\
& =S \cdot \ln K_{\mathrm{OAref}}+C
\end{aligned}
\end{aligned}
$$

where $\Delta U_{\mathrm{OA}}\left(\mathrm{kJ} \mathrm{mol}^{-1}\right)$ is the internal energy of phase transfer between octanol and air and $C$ is the integration constant. It is assumed that the energies of phase transfer are independent of temperature in the temperature range extending from environmentally relevant range to the temperatures of gas chromatographic runs.

A plot of $\ln \left(t_{\mathrm{Ri}} / t_{\mathrm{Rref}}\right)$ versus $\ln K_{\mathrm{OAref}}$ gives a straight line with slope $\left.S=\left[\Delta U_{\mathrm{OAi}} / \Delta U_{\mathrm{OAref}}\right)-1\right]$ and intercept $C$ (Eq. (6)). $\left(t_{\mathrm{Ri}} / t_{\mathrm{Rref}}\right)$ is the relative retention time at the temperature where the reference compound has the octanol-air partition coefficient ( $\left.K_{\mathrm{OAref}}\right)$. The $K_{\mathrm{OAi}}$ of compound $i$ at a reference temperature was obtained using Eq. (5) where $K_{\mathrm{OAref}}$ is the $K_{\mathrm{OA}}$ of the reference compound at that temperature. $\left(\Delta U_{\mathrm{OAi}} / \Delta U_{\mathrm{OAref}}\right)=$ $S+1$ and $C$ were obtained from the slope and intercept of Eq. (6).

In this study, pyrene was used as the standard reference compound to determine the $K_{\mathrm{OAi}}$ for carbazole.
Using the generator column technique, Harner and Bidleman (1998b) measured $K_{\mathrm{OA}}$ values for selected PAHs (fluorene, phenanthrene, pyrene, and fluoranthene) as a function of temperature $(T, K)$. The following equation was obtained for pyrene:

$$
\log K_{\mathrm{OA}}=-4.56+3985(T, K)^{-1}, \quad r^{2}=0.990
$$

Eq. (7) was used to calculate $K_{\text {OAref }}$ values in Eqs. (5) and (6) at the temperatures that isothermal GC retention times were determined.

\subsection{Supercooled liquid vapor pressure}

$P_{\mathrm{L}}$ values were determined from the GC retention times following the procedure used by Lei et al. (2002) and Wong et al. (2001). The vapor pressure $\left(P_{\mathrm{GC}}\right)$ at $25^{\circ} \mathrm{C}$ was calculated using:

$\ln P_{\mathrm{GC}}=\left(\Delta H_{\text {vap }} / \Delta H_{\text {vap-ref }}\right) \ln P_{\text {Lref }}+C$

where $P_{\mathrm{Lref}}(\mathrm{Pa})$ and $\Delta H_{\text {vap-ref }}\left(\mathrm{kJ} \mathrm{mol}^{-1}\right)$ are the liquid phase vapor pressure at $25^{\circ} \mathrm{C}$ and the enthalpy of vaporization of a standard reference compound. The enthalpies of vaporization are assumed to be constant over the studied temperature range $\left(25^{\circ} \mathrm{C}\right.$ to temperatures of $\mathrm{GC}$ retention time measurements). The ratio of enthalpies $\left(\Delta H_{\text {vap }} / \Delta H_{\text {vap-ref }}\right)$ and the constant $C$ in Eq. (8) were obtained by linearly regressing the logarithm of the ratios of the measured isothermal GC retention times $\left(t_{\mathrm{R}} / t_{\mathrm{R} r e f}\right)$ at each temperature against the logarithm of the vapor pressure of a reference compound at that temperature using the following relation (Wong et al., 2001; Lei et al., 2002):

$$
\ln \left(t_{\mathrm{R}} / t_{\text {Rref }}\right)=\left[1-\left(\Delta H_{\text {vap }} / \Delta H_{\text {vap-ref }}\right)\right] \ln P_{\text {Lref }}-C
$$

Eq. (9) assumes that the infinite dilution activity coefficients in the stationary phase of the GC column are the same for the analyte and the compound used as reference. Since this is an approximation, $P_{\mathrm{GC}}$ may not be always identical to supercooled liquid vapor pressure $\left(P_{\mathrm{L}}\right)$. Therefore, calibration of the method with closely related compounds is recommended (Wong et al., 2001; Lei et al., 2002).

In this study, pyrene was used as the standard reference compound. Lei et al. (2002) recently compiled several determinations of temperature dependent solid vapor pressures $\left(P_{\mathrm{S}}\right)$ for pyrene. $P_{\mathrm{S}}$ was converted to $P_{\mathrm{L}}$ using the values for the entropy of fusion and melting point temperature and regressed against reciprocal absolute temperature. Following equation was obtained (Lei et al., 2002):

$$
\begin{aligned}
& \log P_{\mathrm{L}}(\mathrm{Pa})=11.70-4164(T, K)^{-1}, \\
& r^{2}=0.999 \text { (pyrene) }
\end{aligned}
$$

$P_{\text {Lref values in Eqs. (8) and (9) were calculated using }}$ Eq. (10). 


\section{Results and discussion}

\subsection{Henry's law constant}

$H^{\prime}$ measurements were conducted at four different environmental temperatures including 35, 25, 15 and $5{ }^{\circ} \mathrm{C}$. At every temperature, experiments were replicated 3 times $(n=3)$ while at $25^{\circ} \mathrm{C}$ they were replicated 5 times $(n=5)$. However, since the aqueous concentration was zero at the end of the sampling period, it was not possible to determine $H^{\prime}$ values of phenanthrene for few experiments. The measured Henry's law constant values of carbazole and phenanthrene at four different temperatures are presented in Table 1 . The good agreement between the $H$ values for phenanthrene measured at different temperatures in this study and those reported by previous studies indicates the consistency of the results of the present study (Mackay, 1982; Fendinger and Glotfelty, 1990; Alaee et al., 1996; De Maagd et al., 1998; Bamford et al., 1999) (Fig. 1).

The $H^{\prime}$ values decreased with temperature. There is a strong correlation between the experimental $H^{\prime}$ values of carbazole and temperature (Fig. 2). The following equations were obtained for $H^{\prime}$ versus temperature regressions of carbazole and phenanthrene:

$$
\begin{gathered}
\ln H^{\prime}=-3982(T, K)^{-1}+1.01, \\
r^{2}=0.97(\text { carbazole) } \\
\ln H^{\prime}=-7419(T, K)^{-1}+18.36, \\
r^{2}=0.98 \text { (phenanthrene) }
\end{gathered}
$$

The enthalpies of phase change $\left(\Delta H_{\mathrm{H}}, \mathrm{kJ} \mathrm{mol}^{-1}\right)$ calculated using the slopes $(B)$ of Eqs. (11) and (12) and ideal gas constant $(R)$ were $33.1-61.7 \mathrm{~kJ} \mathrm{~mol}^{-1}$ for carbazole and phenanthrene, respectively. By comparison, the values of $29.3 \mathrm{~kJ} \mathrm{~mol}^{-1}$ (Alaee et al., 1996) and $47.3 \mathrm{~kJ} \mathrm{~mol}^{-1}$ (Bamford et al., 1999) were previously reported for phenanthrene. However, there are no reported $\Delta H_{\mathrm{H}}$ values for carbazole in the literature. Previously reported $\Delta H_{\mathrm{H}}$ ranges for other SOCs are 14.5-167 kJ mol ${ }^{-1}$ for PCBs (Bamford et al., 2000) and $16.8-87.8 \mathrm{~kJ} \mathrm{~mol}^{-1}$ for pesticides (Staudinger and Roberts, 2001). $\Delta H_{\mathrm{H}}$ value for carbazole determined in this study was within these ranges.

The $H$ value for carbazole was not measured previously but it was estimated by bond contribution and group contribution methods at $25^{\circ} \mathrm{C}$ (EPA, 2004). $H$

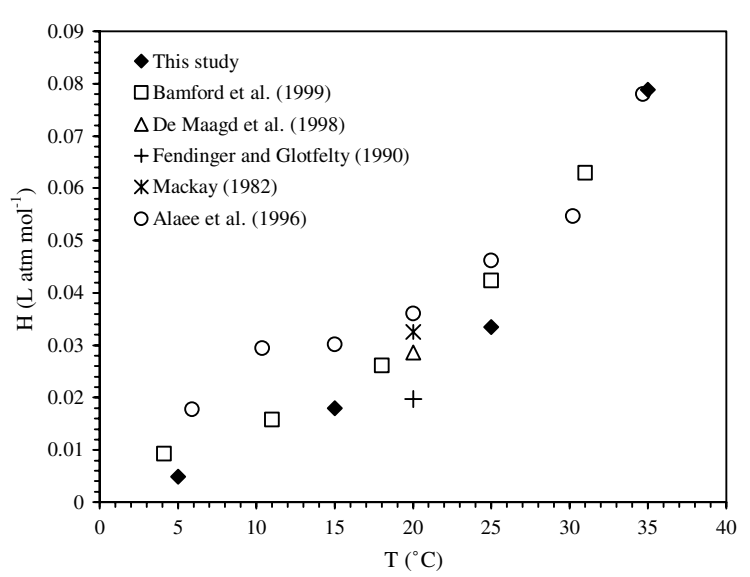

Fig. 1. Comparison of Henry's law constant of phenanthrene with previous studies.

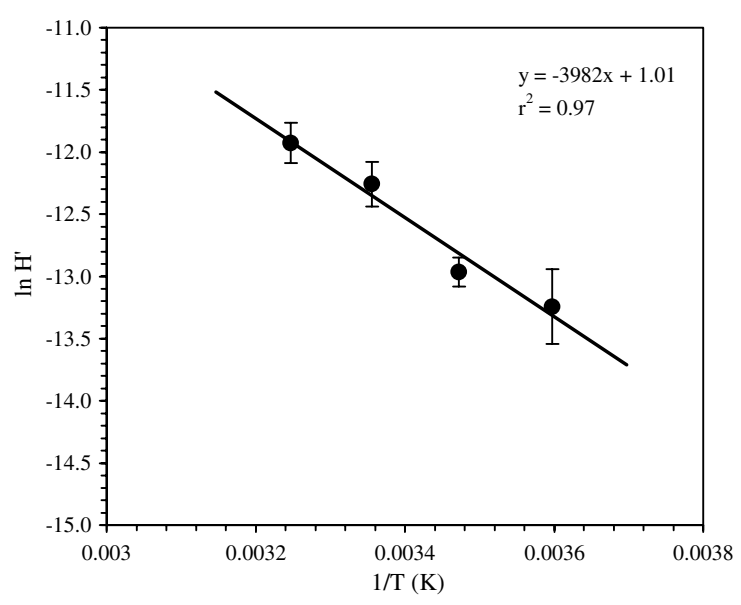

Fig. 2. Correlation of $\ln H^{\prime}$ (carbazole) with $1 / T(\mathrm{~K})$.

for carbazole was also estimated using vapor pressure and water solubility estimations and vapor pressures determined in this study and the experimental water solubility values reported by Miller and Hawthorne (1998) ( $\left.H=P_{\mathrm{v}} / C_{\mathrm{s}}\right)$. The comparison of these results was illustrated in Fig. 3. The results of this study agreed well with the estimation of bond contribution at $25^{\circ} \mathrm{C}$. Measured to estimated ratios ranged between 0.2 and 18 for $H$ values at different temperatures (Fig. 3). It is not possible to offer an explanation for the difference between the

Table 1

The Henry's law constants of phenanthrene and carbazole (average $\pm \mathrm{SD}$ ) as a function of temperature

\begin{tabular}{lll}
\hline Temperature $\left({ }^{\circ} \mathrm{C}\right)$ & $H_{\text {phenanthrene }}\left(\mathrm{L} \mathrm{atm} \mathrm{mol}^{-1}\right)$ & $\left.H_{\text {carbazole }}(\mathrm{L} \mathrm{atm} \mathrm{mol})^{-1}\right)$ \\
\hline 35 & $0.0789(n=1)$ & $0.000167 \pm 0.000028(n=3)$ \\
25 & $0.0335 \pm 0.0083(n=3)$ & $0.000116 \pm 0.000020(n=5)$ \\
15 & $0.0180(n=2)$ & $0.000055 \pm 0.000006(n=3)$ \\
5 & $0.0049(n=2)$ & $0.000040 \pm 0.000011(n=3)$ \\
\hline
\end{tabular}




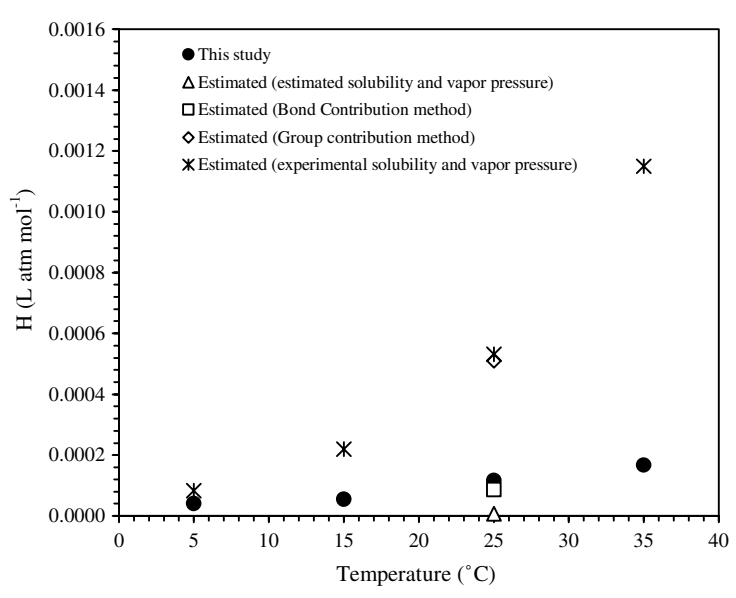

Fig. 3. Comparison of experimental Henry's law constant of carbazole and estimated values.

estimated and experimental values. However, these results demonstrate the importance of experimental determination of the temperature dependence of $H$ for carbazole to accurately predict of its fate and transport under different environmental conditions.

\subsection{Octanol-air partition coefficient}

The relationships between $\ln \left(t_{\mathrm{R}} / t_{\mathrm{R} \text { ref }}\right)$ and $\ln K_{\mathrm{OAref}}$ and $\ln P_{\text {Lref }}$ are presented in Fig. 4 (Eqs. (6) and (9)). These relationships for carbazole were highly linear with very high coefficients of determination $\left(r^{2}\right)$. Phenanthrene was also included in the $K_{\mathrm{OA}}$ and $P_{\mathrm{L}}$ determinations. Table 2 lists determined octanol-air partition coefficients ( $K_{\mathrm{OA}-\mathrm{GC}}$ and $\left.K_{\mathrm{OA}}\right)$ of carbazole and phenan-
Table 2

Uncalibrated $\left(K_{\mathrm{OA}-\mathrm{GC}}\right)$ and calibrated $\left(K_{\mathrm{OA}}\right)$ octanol-air partition coefficients for phenanthrene and carbazole at $25^{\circ} \mathrm{C}$ determined from gas chromatographic retention times using pyrene as reference (average $\pm \mathrm{SD}, n=3$ ), energies of phase transfer $\left(\Delta U_{\mathrm{OA}}\right)$, regression parameters for equation log $K_{\mathrm{OA}}=$ $A+B /(T, K)$, and calculated $K_{\mathrm{OA}}$ values from dimensioness Henry's law constant and octanol-water partition coefficient

\begin{tabular}{|c|c|c|}
\hline & Phenanthrene & Carbazole \\
\hline $\log K_{\mathrm{OA}-\mathrm{GC}}$ & $7.59 \pm 0.0005$ & $7.89 \pm 0.0008$ \\
\hline $\log K_{\mathrm{OA}}$ & $7.68 \pm 0.0014$ & $8.03 \pm 0.0025$ \\
\hline$B$ & 3835 & 4076 \\
\hline$A$ & -5.19 & -5.65 \\
\hline$\Delta H_{\mathrm{OA}}\left(\mathrm{kJ} \mathrm{mol}^{-1}\right)$ & 73.4 & 78.1 \\
\hline $\log K_{\text {ow }}$ & $4.57^{\mathrm{a}}$ & $3.72^{\mathrm{b}}$ \\
\hline$H\left(\mathrm{~L}\right.$ atm $\left.\mathrm{mol}^{-1}\right)$ & 0.0335 & 0.000116 \\
\hline $\log K_{\mathrm{OA}}$ & $7.57^{\mathrm{a}}, 7.43^{\mathrm{c}}$ & $9.04^{\mathrm{c}}$ \\
\hline Factor difference & $1.3,1.8$ & 0.1 \\
\hline
\end{tabular}

a Experimental, Harner and Bidleman (1998b).

b VCCL (2004).

c Calculated.

threne at $25^{\circ} \mathrm{C}$ as well as the intercepts $(A)$ and slopes $(B)$ of the temperature regressions:

$\log K_{\mathrm{OA}}=A+B /(T, K)$

The $K_{\mathrm{OA}-\mathrm{GC}}$ and $K_{\mathrm{OA}}$ values were highly reproducible as indicated by the small standard deviations calculated from independent determinations $(n=3)$.

Recently, a strong correlation was found between the directly measured $\log K_{\mathrm{OA}}$ values of fluorene, phenanthrene, and fluoranthene (between 0 and $40{ }^{\circ} \mathrm{C}$ ) (Harner and Bidleman, 1998b) versus $K_{\mathrm{OA}-\mathrm{GC}}$ determined on a
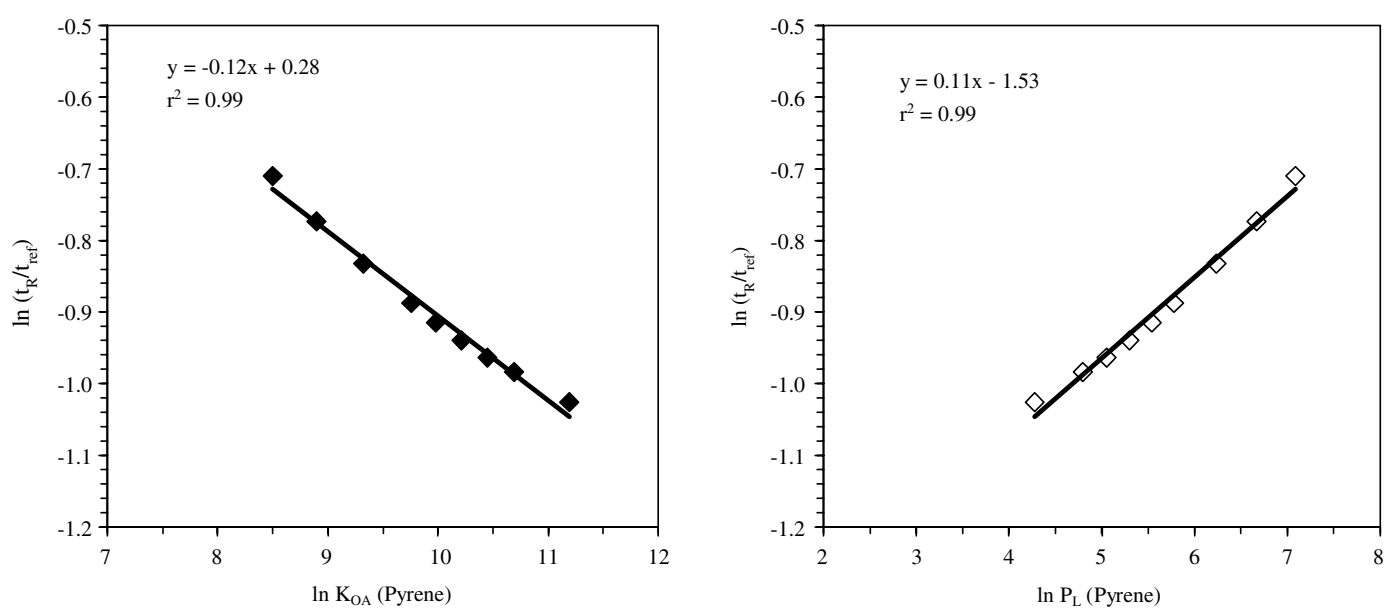

Fig. 4. Relationships between the logarithm of the ratio of the retention times of carbazole to the retention time of the standard reference compound (pyrene) at nine temperatures and the $\ln K_{\mathrm{OA}}$ and $\ln P_{\mathrm{L}}$ values of pyrene at these temperatures calculated from Eqs. (7) and (10). 
same type of GC column used in the present study (Odabasi, 2004):

$$
\begin{aligned}
& \log K_{\mathrm{OA}}=1.16 \log P_{\mathrm{GC}}(\mathrm{Pa})-1.12 \\
& r^{2}=0.98(n=13)
\end{aligned}
$$

Eq. (14) was used to correct the $K_{\mathrm{OA}-\mathrm{GC}}$ values for the systematic deviations from directly measured $K_{\mathrm{OA}}$ values. $K_{\mathrm{OA}-\mathrm{GC}}$ was slightly higher than $K_{\mathrm{OA}}$ (Table 2 ).

$K_{\mathrm{OA}}$ values were also calculated as the ratio of octanol-water partition coefficient $\left(K_{\mathrm{OW}}\right)$ to dimensionless Henry's law constant $\left(H^{\prime}\right)$ (Table 2$)$. The $K_{\mathrm{OA}} / K_{\mathrm{OA}}$ (calculated) ratios were 0.1 and 1.8 for carbazole and phenanthrene, respectively. Similar deviations between the calculated and directly measured $K_{\mathrm{OA}}$ values were reported by previous studies (Harner and Mackay, 1995; Harner and Bidleman, 1998b; Shoeib and Harner, 2002). However, the agreement between the experimentally determined $K_{\mathrm{OA}}(7.57)$ and the one determined in this study (7.68) was very good indicating the consistency of the results.

The internal energies of phase transfer between octanol and air $\left(\Delta U_{\mathrm{OA}}\right)$ were calculated as $(2.303 \mathrm{BR})$ using the slope of Eq. (13) $(B)$ and ideal gas constant $(R)$ (Table 2). $\Delta U_{\mathrm{OA}}$ calculated in this study for phenanthrene $\left(73.4 \mathrm{~kJ} \mathrm{~mol}^{-1}\right)$ agreed well with the value reported by Harner and Bidleman (1998b) $\left(75.5 \mathrm{~kJ} \mathrm{~mol}^{-1}\right)$.

\subsection{Supercooled liquid vapor pressures}

Table 3 presents the determined vapor pressures $\left(P_{\mathrm{GC}}\right.$ and $\left.P_{\mathrm{L}}\right)$ of carbazole and phenanthrene at $25^{\circ} \mathrm{C}$ as well as the intercepts $\left(b_{\mathrm{L}}\right)$ and slopes $\left(m_{\mathrm{L}}\right)$ of the temperature regressions:

$\log P_{\mathrm{L}}(\mathrm{Pa})=m_{\mathrm{L}}(T, K)^{-1}+b_{\mathrm{L}}$

Enthalpies of vaporization $\left(\Delta H_{\mathrm{vap}}\right)$ are also listed. The $P_{\mathrm{GC}}$ and $P_{\mathrm{L}}$ values were highly reproducible as indicated by the small standard deviations calculated from three independent determinations.

Recently, six compounds (acenaphthene, fluorene, phenanthrene, anthracene, fluoranthene, and chrysene) with well established vapor pressures at $25^{\circ} \mathrm{C}$ were used for calibration of $P_{\mathrm{GC}}$ values of PAHs determined using a nonpolar GC column (HP-5 ms, 5\% phenylpolisiloxane $+95 \%$ methylpolisiloxane). $P_{\mathrm{GC}}$ values for calibration compounds were regressed against $P_{\mathrm{L}}$ values compiled by Lei et al. (2002) from previous studies and the following relationship was obtained (Odabasi, 2004):

$$
\begin{aligned}
& \log P_{\mathrm{L}}(\mathrm{Pa})=1.069 \log P_{\mathrm{GC}}(\mathrm{Pa})+0.041, \\
& r^{2}=0.994(n=29)
\end{aligned}
$$

The relationship between $P_{\mathrm{GC}}$ and $P_{\mathrm{L}}$ was linear, the slope was close to 1 and the intercept close to $0 . P_{\mathrm{GC}}$ was only slightly lower than $P_{\mathrm{L}}$ for carbazole and phenanthrene, indicating that calibration procedure has a small effect on calculated $P_{\mathrm{L}}$ values.

The agreement between the $P_{\mathrm{L}}$ value of phenanthrene determined in this study at $25^{\circ} \mathrm{C}$ and one recently reported by Lei et al. (2002) was excellent. The agreement between the $P_{\mathrm{L}}$ of carbazole and literature values was reasonable (Table 3 ).

Enthalpies of vaporization $\left(\Delta H_{\mathrm{vap}}\right)$ were calculated as $\left(2.303 m_{\mathrm{L}} R\right)$ using the slope of Eq. (15) $\left(m_{\mathrm{L}}\right)$ and ideal gas constant $(R)$ (Table 2). $\Delta H_{\text {vap }}$ for phenanthrene $\left(71.3 \mathrm{~kJ} \mathrm{~mol}^{-1}\right)$ was similar to one recently reported by Lei et al. (2002) (72.2 $\left.\mathrm{kJ} \mathrm{mol}^{-1}\right)$. However, there were no previously reported values for carbazole.

\subsection{Gas/particle partitioning}

Partitioning of atmospheric organic compounds between the gas and particle phases is parameterized using the gas/particle partition coefficient, $K_{\mathrm{p}}\left(\mathrm{m}^{3} \mu \mathrm{g}^{-1}\right)$ (Harner and Bidleman, 1998a):

$K_{\mathrm{p}}=\left(C_{\mathrm{p}} / C_{\mathrm{TSP}}\right) / C_{\mathrm{g}}$

where $C_{\mathrm{p}}$ and $C_{\mathrm{g}}$ are the organic compound concentrations in the particulate and gas phases, respectively $\left(\mu \mathrm{g} \mathrm{m}^{-3}\right)$, and $C_{\mathrm{TSP}}$ is the concentration of total suspended particles in the air $\left(\mu \mathrm{g} \mathrm{m}^{-3}\right)$.

The octanol-air partitioning coefficient $\left(K_{\mathrm{OA}}\right)$ can be used to predict $K_{\mathrm{p}}$ with the assumption of predominant distribution process is absorption (Harner and Bidleman, 1998a). The relationship between $K_{\mathrm{P}}$ and $K_{\mathrm{OA}}$ is

Table 3

Uncalibrated $\left(P_{\mathrm{GC}}\right)$ and calibrated $\left(P_{\mathrm{L}}\right)$ vapor pressures for carbazole and phenanthrene at $25^{\circ} \mathrm{C}$ determined from gas chromatographic retention times (average $\pm \mathrm{SD}, n=3$ ), enthalpies of vaporization $\left(\Delta H_{\mathrm{vap}}\right.$ ), and regression parameters for the equation $\log P_{\mathrm{L}}(\mathrm{Pa})=m_{\mathrm{L}}(T, K)^{-1}+b_{\mathrm{L}}$

\begin{tabular}{lllllll}
\hline & $\log P_{\mathrm{L}-\mathrm{GC}}(\mathrm{Pa})$ & $\log P_{\mathrm{L}}(\mathrm{Pa})$ & $m_{\mathrm{L}}$ & $b_{\mathrm{L}}$ & $\Delta H_{\text {vap }}\left(\mathrm{kJ} \mathrm{mol}^{-1}\right)$ & $\log P_{\mathrm{L}}(\mathrm{Pa})(\operatorname{literature})$ \\
\hline Phenanthrene & $-1.05 \pm 0.001$ & $-1.08 \pm 0.002$ & -3726 & 11.43 & -71.3 & $-1.1^{\mathrm{a}}$ \\
Carbazole & $-1.35 \pm 0.002$ & $-1.40 \pm 0.002$ & -3948 & 11.84 & -75.6 & $-1.7^{\mathrm{b}},-2.7^{\mathrm{c}}$ \\
\hline
\end{tabular}

\footnotetext{
${ }^{\text {a }}$ Lei et al. (2002).

b EPA (2004).

c Liang and Pankow (1996).
} 
$K_{\mathrm{P}}=\left(f_{\mathrm{OM}} \mathrm{MW}_{\mathrm{OCT}} \zeta_{\mathrm{OCT}}\right) K_{\mathrm{OA}} /\left(\rho_{\mathrm{OCT}} \mathrm{MW}_{\mathrm{OM}} \zeta_{\mathrm{OM}} 10^{12}\right)$

where $f_{\mathrm{OM}}$ is the fraction of organic matter phase on TSP, $\mathrm{MW}_{\text {OCT }}$ and $\mathrm{MW}_{\mathrm{OM}}$ are the mean molecular weights of octanol and the organic matter phase $\left(\mathrm{g} \mathrm{mol}^{-1}\right), \rho_{\text {OCT }}$ is the density of octanol $\left(0.820 \mathrm{~kg} \mathrm{l}^{-1}\right)$, $\zeta_{\text {OCT }}$ is the activity coefficient of the absorbing compound in octanol, $\zeta_{\mathrm{OM}}$ is the activity coefficient of the compound in the organic matter phase. With the assumptions that $\zeta_{\mathrm{OCT}} / \zeta_{\mathrm{OM}}$ and $\mathrm{MW}_{\mathrm{OCT}} / \mathrm{MW}_{\mathrm{OM}}=1$, Eq. (18) can be written as

$\log K_{\mathrm{P}}=\log K_{\mathrm{OA}}+\log f_{\mathrm{OM}}-11.91$

Strong association of PAHs with soot particles in soot-water systems suggests that besides absorption, adsorption partitioning could also be an important sorption mechanism in the atmosphere. Therefore, the following equation for the overall gas-particle partition coefficient that accounts for both organic matter absorption and soot carbon adsorption was derived by Dasch and Eisenreich (2000):

$$
\begin{aligned}
K_{\mathrm{P}}= & {\left[\left(f_{\mathrm{OM}} \mathrm{MW}\right.\right.} \\
& \left.+\left[\left(f_{\mathrm{EC}} a_{\mathrm{EC}}\right) K_{\mathrm{SA}} \zeta_{\mathrm{OCT}}\right) a_{\mathrm{AC}} 10^{12}\right]
\end{aligned}
$$

where $f_{\mathrm{EC}}$ is the fraction of elemental carbon in the aerosol, $a_{\mathrm{EC}}$ and $a_{\mathrm{AC}}$ are the specific surface areas of elemental carbon and activated carbon, respectively; $K_{\mathrm{SA}}$ is the soot-air partition coefficient which can be obtained from the ratio of soot-water partition coefficient $\left(K_{\mathrm{SW}}\right)$ and temperature adjusted dimensionless Henry's law constant $\left(H^{\prime}\right)\left(K_{\mathrm{SA}}=K_{\mathrm{SW}} / H^{\prime}\right)$. Elemental carbon and octanol are the surrogates for the soot carbon in adsorptive partitioning, and organic matter in absorptive partitioning, respectively.

The gas and particle phase carbazole concentrations measured previously in Chicago, IL in 1995 was used for gas/particle partitioning modeling (Odabasi et al., 1999). The experimental and modeled $K_{\mathrm{p}}$ values for carbazole were calculated using Eqs. (17), (19), and (20). The influence of temperature on $K_{\mathrm{OA}}$ and $H^{\prime}$ was taken into account using Eqs. (13) and (11), respectively. $K_{\mathrm{SW}}$ for carbazole was calculated using the following relationship developed by Jonker and Koelmans (2002) for PAHs:

$$
\begin{aligned}
\log K_{\mathrm{SW}}= & 0.03 V_{\mathrm{mol}}+1.99 f_{\mathrm{AC}}+3.75 \mathrm{TPV} \\
& +0.95 f_{\mathrm{SC}}-0.003 \mathrm{SSA}-1.491
\end{aligned}
$$

where $V_{\mathrm{mol}}$ is the molar volume of the compound $\left(161.1 \mathrm{~cm}^{3} \mathrm{~mol}^{-1}\right.$ for carbazole), $f_{\mathrm{AC}}$ is the fraction of amorphous carbon (0.412), TPV is the total pore volume $\left(0.155 \mathrm{~cm}^{3} \mathrm{~g}^{-1}\right), f_{\mathrm{SC}}$ is the fraction of soot carbon $(0.361)$

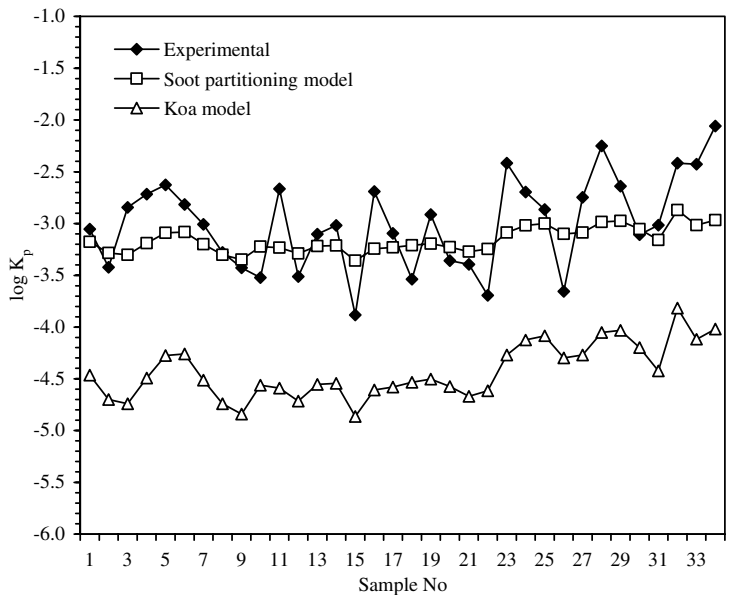

Fig. 5. Comparison of experimental and modeled $\log K_{\mathrm{p}}$ values for carbazole.

and, SSA is the specific surface area $\left(62.7 \mathrm{~m}^{2} \mathrm{~g}^{-1}\right)$ of the sorbent (diesel soot). Using Eq. (21) $\log K_{\mathrm{SW}}$ for carbazole was calculated as 4.90 at $20^{\circ} \mathrm{C}$. Offenberg and Baker (2000) reported that the organic matter and elemental carbon fractions were 0.26 and 0.034 , respectively for the aerosol samples collected during the summer 1994 in Chicago, IL. These values were used in the prediction of $K_{\mathrm{p}}$. It was assumed that $a_{\mathrm{EC}} / a_{\mathrm{AC}}$ was equal to 1 . Under these assumptions, modeled $K_{\mathrm{p}}$ values were calculated using Eq. (19) for absorptive partitioning and Eq. (20) for both absorptive and adsorptive partitioning. The modeled results were compared with the measured values of $K_{\mathrm{p}}$ in Fig. 5 for each sampling period. Octanol based absorptive partitioning model consistently predicted lower partition coefficients for all sampling periods. However, there is a very good overall agreement between the measured $K_{\mathrm{p}}$ and soot-based model predictions. Ratios of measured/modeled partition coefficients ranged between 4.4 and $91(35 \pm 24$, average $\pm \mathrm{SD}$ ) for $K_{\mathrm{OA}}$ model indicating that this model significantly underpredicted the experimental $K_{\mathrm{p}}$ values. $K_{\mathrm{SA}}$ model predictions were significantly better and measured to modeled ratios ranged between 0.3 and 8.1 $(2.0 \pm 1.7$, average $\pm \mathrm{SD})$.

\section{References}

Alaee, M., Whittal, R., Strachan, W.M.J., 1996. The effect of water temperature and composition on Henry's law constant for various PAHs. Chemosphere 32, 1153-1164.

Bamford, H.A., Poster, D.L., Baker, J.E., 1999. Temperature dependence of Henry's law constants of thirteen polycyclic aromatic hydrocarbons between $4{ }^{\circ} \mathrm{C}$ and $31^{\circ} \mathrm{C}$. Environmental Toxicology and Chemistry 18, 1905-1912. 
Bamford, H.A., Poster, D.L., Baker, J.E., 2000. Henry's law constants of polychlorinated biphenyl congeners and their variation with temperature. Journal of Chemical and Engineering Data 45, 1069-1074.

Benedik, M.J., Gibbs, P.R., Riddle, R.R., Willson, R.C., 1998. Microbial denitrogenation of fossil fuels. Trends in Biotechnology 16, 390-395.

Bidleman, T.F., 1988. Atmospheric processes: wet and dry deposition of organic compounds are controlled by their vapor-particle partitioning. Environmental Science and Technology 22, 361-367.

Dasch, J., Eisenreich, S.J., 2000. Adsorption onto aerosol carbon soot carbon dominates gas-particle partitioning of polycyclic aromatic hydrocarbons. Environmental Science and Technology 34, 3690-3697.

De Maagd, P.G.J., Ten Hulscher, D.T.E.M., Van den Heuvel, H., Opperhuizen, A., Sijm, D.T.H.M., 1998. Physicochemical properties of polycyclic aromatic hydrocarbons: aqueous solubilities, $n$-octanol/water partition coefficients, and Henry's law constants. Environmental Toxicology And Chemistry 17, 251-257.

EPA, 2004. EPI Suite estimation software (V3.11), Available from: http://www.epa.gov/oppt/exposure/docs/episuitedl. htm.

Fendinger, N.J., Glotfelty, D.E., 1990. Henry's law constants for selected pesticides, PAHs, and PCBs. Environmental Toxicology and Chemistry 9, 731-735.

Finizio, A., Mackay, D., Bidleman, T.F., Harner, T., 1997. Octanolair partition coefficient as a predictor of partitioning of semivolatile organic chemicals. Atmospheric Environment 31, 2289-2296.

Grosser, R.J., Warshawsky, D., Vestal, J.R., 1995. Mineralization of polycyclic and N-heterocyclic aromatic compounds in hydrocarbon contaminated soils. Environmental Toxicology and Chemistry 14, 375-382.

Harner, T., Bidleman, T.F., 1998a. Octanol-air partition coefficient for describing particle/gas partitioning of aromatic compounds in urban air. Environmental Science and Technology 32, 1494-1502.

Harner, T., Bidleman, T.F., 1998b. Measurement of octanolair partition coefficients for polycyclic aromatic hydrocarbons and polychlorinated naphthalenes. Journal of Chemical and Engineering Data 43, 40-46.

Harner, T., Bidleman, T.F., 1996. Measurements of octanol-air partition coefficients for polychlorinated biphenyls. Journal of Chemical and Engineering Data 41, 895-899.

Harner, T., Mackay, D., 1995. Measurements of octanol-air partition coefficients for chlorobenzenes, PCBs and DDT. Environmental Science and Technology 29, 1599-1606.

Harner, T., Shoheib, M., 2002. Measurements of octanol-air partition coefficients $\left(K_{\mathrm{OA}}\right)$ for polybrominated diphenyl ethers: predicting partitioning in the environment. Journal of Chemical and Engineering Data 47, 228-232.

Harner, T., Green, N.J.L., Jones, K.C., 2000. Measurements of octanol-air partition coefficients for PCDD/Fs: a tool in assessing air-soil equilibrium status. Environmental Science and Technology 34, 3109-3114.

Johansen, S.S., Hansen, A.B., Mosbaek, H., Arvin, E., 1997. Identification of heteroatomic and other organic compounds in ground water at creosote-contaminated sites in
Denmark. Ground Water Monitoring and Remediation 17, 106-115.

Jonker, M.T.O., Koelmans, A.A., 2002. Sorption of polycyclic aromatic hydrocarbons and polychlorinated biphenyls to soot and soot-like materials in the aqueous environment: mechanistic considerations. Environmental Science and Technology 36, 3725-3734.

Lei, Y.D., Chankalal, R., Chan, A., Wania, F., 2002. Supercooled liquid vapor pressures of the polycyclic aromatic hydrocarbons. Journal of Chemical and Engineering Data 47, 801-806.

Lei, Y.D., Wania, F., Shiu, W.Y., 1999. Vapor pressures of polychlorinated naphthalenes. Journal of Chemical and Engineering Data 44, 577-582.

Liang, C., Pankow, J.F., 1996. Gas/particle partitioning of organic compounds to environmental tobacco smoke: partitioning coefficient measurements by desorption and comparison to urban particulate material. Environmental Science and Technology 30, 2800-2805.

Mackay, D., 1982. Correlation of bioconcentration factors. Environmental Science and Technology 16, 274-278.

Miller, D.J., Hawthorne, S.B., 1998. Solubility of polycyclic aromatic hydrocarbons in subcritical water from $298 \mathrm{~K}$ to 498 K. Journal of Chemical and Engineering Data 43, 10431047.

Odabasi, M., 2004. Unpublished results.

Odabasi, M., Vardar, N., Tasdemir, Y., Sofuoglu, A., Holsen, T.M., 1999. Polycyclic aromatic hydrocarbons in Chicago air. The Science of the Total Environment 227, 5767.

Offenberg, J.H., Baker, J.E., 2000. Aerosol size distributions of elemental and organic carbon in urban and overwater atmospheres. Atmospheric Environment 34, 15091517.

Pankow, J.F., 1987. Review and comparative analysis of the theories on partitioning between the gas and aerosol particulate phases in the atmosphere. Atmospheric Environment 22, 2275-2283.

Ross, A.B., Jones, J.M., Chaiklangmuang, S., Pourkashanian, M., Williams, A., Kubica, K., Andersson, J.T., Kerst, M., Danihelka, P., Bartle, K.D., 2002. Measurement and prediction of the emission of pollutants from the combustion of coal and biomass in a fixed bed furnace. Fuel 81 , 571-582.

Shoeib, M., Harner, T., 2002. Using measured octanol-air partition coefficients to explain environmental partitioning of organochlorine pesticides. Environmental Toxicology and Chemistry 21, 984-990.

Smith, C.J., Hansch, C., 2000. The relative toxicity of compounds in mainstream cigarette smoke condensate. Food and Chemical Toxicology 38, 637-646.

Staudinger, J., Roberts, P.V., 2001. A critical compilation of Henry's law constant temperature dependence relations for organic compounds in dilute aqueous solution. Chemosphere 44, 561-576.

Su, Y., Lei, Y.D., Daly, G.L., Wania, F., 2002. Determination of octanol-air partition coefficient $\left(K_{\mathrm{OA}}\right)$ values for chlorobenzenes and polychlorinated naphthalenes from gas chromatographic retention times. Journal of Chemical and Engineering Data 47, 449-455. 
Virtual Computational Chemistry Laboratory (VCCL), 2004. Available from: http://146.107.217.178/lab/alogps/start.html.

Wania, F., Lei, Y.D., Harner, T., 2002. Estimating octanol-air partition coefficients of nonpolar semivolatile organic compounds from gas chromatographic retention times. Analytical Chemistry 74, 3476-3483.
Williams, P.T., Nazzal, J.M., 1998. Polycyclic aromatic hydrocarbons in shale oils: influence of process conditions. Environmental Technology 19, 775-787.

Wong, A., Lei, Y.D., Alae, M., Wania, F., 2001. Vapor pressures of polybrominated diphenyl ethers. Journal of Chemical and Engineering Data 46, 239-242. 